\title{
Stress analysis of a link for slat chain conveyor
}

\author{
Veselin Tsonev 1,*, Georgi Stoychev ${ }^{1}$, Emanuil Chankov ${ }^{2}$ \\ ${ }^{1}$ Technical University - Sofia, "Strength of Materials" Department, 8 Kliment Ohridski Blvd., 1000 Sofia, Bulgaria \\ ${ }^{2}$ Visteon Electronics Bulgaria
}

\begin{abstract}
This paper analyzes stresses in a link of a slat chain conveyor loaded with rock mass. Tensometric data and results from numerical simulation with Finite Element Method (FEM) are used. The tensometric measurements are performed in real life conditions. For numerical simulation an adequate model with FEM has been created. The adequacy of the model is confirmed by the comparison of the experimental and numerical results. The factor of safety used in the design of the conveyor links is determined.
\end{abstract}

\section{Introduction}

There are many investigations devoted to stress analysis of roller chains. The roller chains are widely used as driving members of escalators and conveyors.

The stress analysis of chain links using Finite Element Method (FEM) was examined by Antonescu [1]. The results were verified with photo-elastic data.

In [2] the FEA was applayed in order to replace mild stel roller conveyor links by different composite materials.

Noguchi et al. investigated static stresses and some weight saiving design of a link plate roller chain using FEM [3].

Jagtap et al. applied strain gages to analyze the behavior of roller conveyor chain strip [4].

Slat chain conveyors for transportation of rock material work in severe, abrasive environment. This in turn is associated with an increased factor of safety in their design [5]. The normal operation of the conveyor is of the highest priority due to the high cost of the down time and the interruption of the production process. Proper slat chain conveyor design is essential to ensure their long service life.

The reason for studying the conveyor in present paper is failure related to the destructions of a conveyor links.

The conveyor takes material from a bunker and transfers it to a belt conveyor for further processing. The leading wheel of the conveyor is at the top. Fig. 1 shows the model of the conveyor.

The main characteristics of the conveyor are:

- Number of links on the loaded part - 101 per chain;

- Weight per link $-35 \mathrm{~kg}$;

- Number of slats on the loaded part - 101 per chain;

- Weight per slat $-300 \mathrm{~kg}$;

- Length of the conveyor - $26 \mathrm{~m}$;

- Length with material - $25 \mathrm{~m}$;

- Declination $-24^{\circ}$;
- Material (width, height, mass density) - $2 \mathrm{~m}, 1,5 \mathrm{~m}$, $1,8 \mathrm{t} / \mathrm{m}$;

- Capacity $-1800 \mathrm{t} / \mathrm{h}$

Fig. 2 shows a link of the conveyor. The chain link is manufactured from steel with the following mechanical properties:

- Elasticity modulus $-E=2,1.10^{11} \mathrm{~Pa}$;

- Poisson's ratio $-v=0,28$;

- Yield strength $-R_{p 0,2}=640 \mathrm{MPa}$.

The task is to assess the factor of safety and to compare it with the one required in the design of slat chain conveyors.

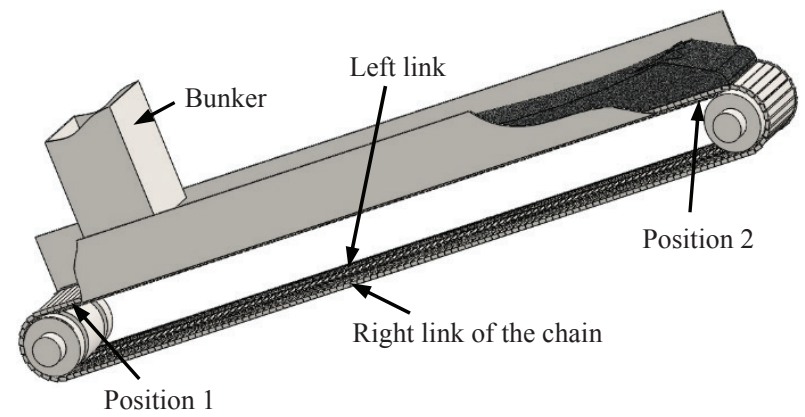

Fig. 1. Model of the conveyor.

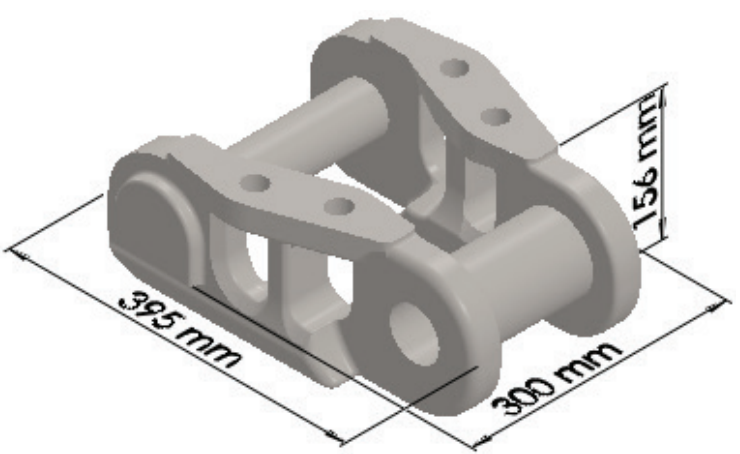

Fig. 2. Conveyor link.

\footnotetext{
*Corresponding author: gstojch@tu-sofia.bg
} 


\section{Experimental study}

The method of calculating the stresses from the measured strains in free of loading plane is widely used in engineering practice [6]. In this case the principal stress in the perpendicular to this plane direction is equal to zero. The normal strains $\left(\varepsilon_{a}, \varepsilon_{b}, \varepsilon_{c}\right)$ at a point on the free surface in directions $a, b$ and $c$ are determined using strain rosette. The two other principal stresses $\left(\sigma^{\prime}\right.$ and $\left.\sigma^{\prime \prime}\right)$ are calculated. The principal stresses are arranged in descending order $\sigma_{1} \geq \sigma_{2} \geq \sigma_{3}$. Using the principal stresses von Mises stress $\left(\sigma_{e k v}^{V M}\right)$ is calculated.

Fig. 3 shows pictures of broken conveyor links. The destruction is in the areas opposite to the holes of the conveyor plates at the locations of the geometric stress concentrators. These places are not suitable for mounting strain gauges. Fig. 4 shows the selected zone of the left and the right conveyor links in which the strain gauges are installed.

Fig. 5 shows schemata of strain gauge measurement. A rectangular strain gauge is mounted on the selected area. To measure strains in directions $a, b$ and $c$ Wheatstone quarter bridge is used. The quarter bridge consists of stressed strain gauge and unstressed strain gauge for temperature compensation. The strain gauge for temperature compensation is mounted on an unstressed steel plate. The quarter gauge bridges are connected to multi-channel strain gauge Data Acquisition system -1 , which is connected to PC -2 .

Table 1 shows designations of the mounted gauges.
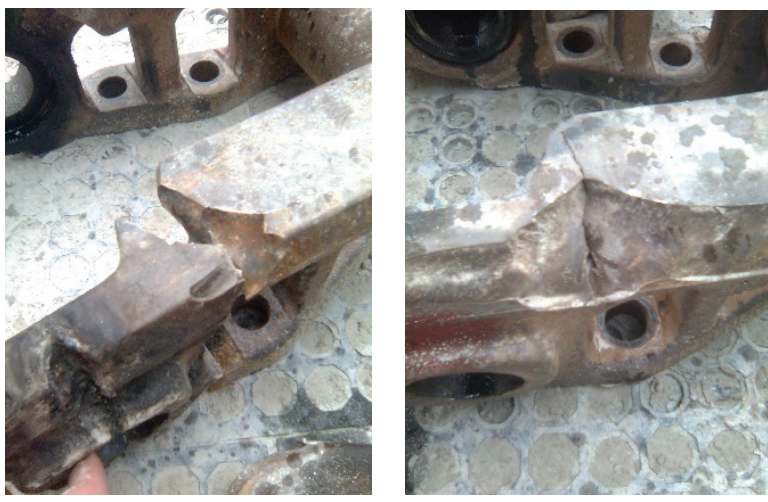

Fig. 3. Pictures of broken conveyor links.

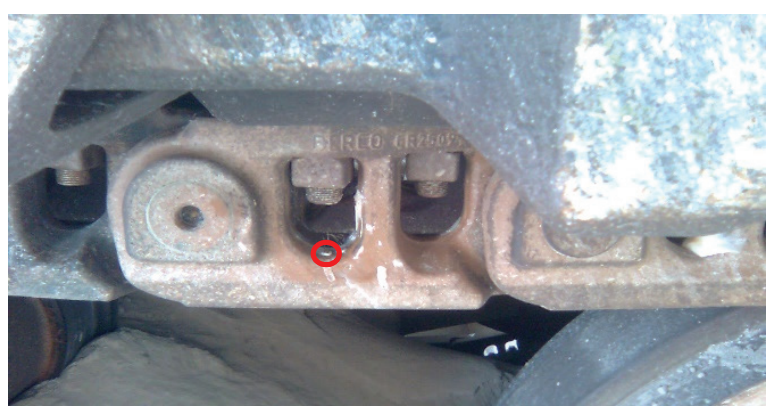

Fig. 4. Zone in which the strain gauges are installed.

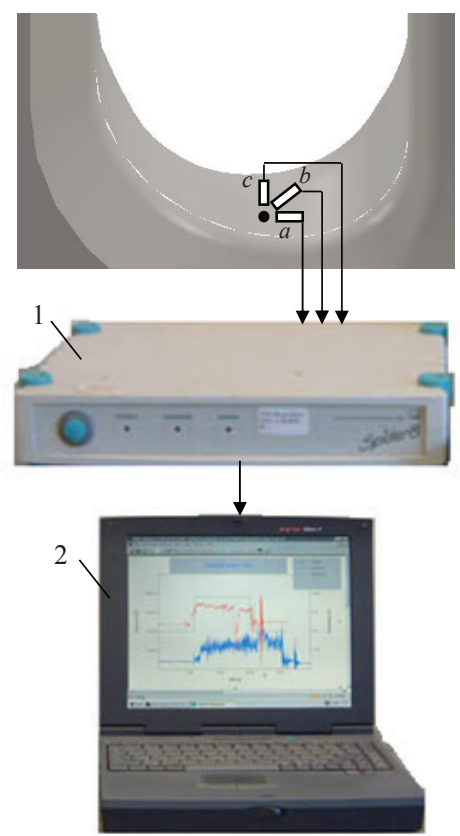

Fig. 5. Scheme of strain gauge measurement.

Table 1. Designations of the mounted gauges.

\begin{tabular}{|c|c|c|}
\hline Link & Direction & Designation \\
\hline \multirow{7}{*}{ Right } & $\begin{array}{c}45^{\circ} \text { with respect to the } \\
\text { axis of the chain } \\
\text { (direction } b \text { ) }\end{array}$ & CH1D45 \\
\cline { 2 - 3 } & $\begin{array}{c}\text { Aligned with the axis } \\
\text { of the chain } \\
\text { (direction } a)\end{array}$ & CH2D0 \\
\cline { 2 - 3 } & $\begin{array}{c}90^{\circ} \text { with respect to the } \\
\text { axis of the chain } \\
\text { (direction } c)\end{array}$ & CH3D90 \\
\hline \multirow{7}{*}{ Left } & $\begin{array}{c}45^{\circ} \text { with respect to the } \\
\text { axis of the chain }\end{array}$ & CH4L45 \\
\cline { 2 - 3 } & $\begin{array}{c}\text { Aligned with the } \\
\text { axis of the chain }\end{array}$ & CH5L0 \\
\cline { 2 - 3 } & $\begin{array}{c}90^{\circ} \text { with respect to the } \\
\text { axis of the chain }\end{array}$ & CH6L90 \\
\hline
\end{tabular}

The following measurements were made:

Measurement 1 - The links on which the gauges are mounted are located at the bottom end of the conveyor before the bunker. The bunker is filled and the machine starts pouring material onto the conveyor. The measurement of the strains starts from position 1 (Fig. 1), in which the links are slightly after the lower shaft, to position 2 (Fig. 1), in which the links are slightly before the upper shaft;

Measurement 2 - The links on which the gauges are mounted are located at the bottom of the conveyor before the bunker. The machine runs with a full bunker and material loaded on the conveyor. The measurement of the strains starts from position 1, located slightly after the lower shaft, to position 2, located slightly before the upper shaft.

Figures 6 and 7 show the results from the measurements. 

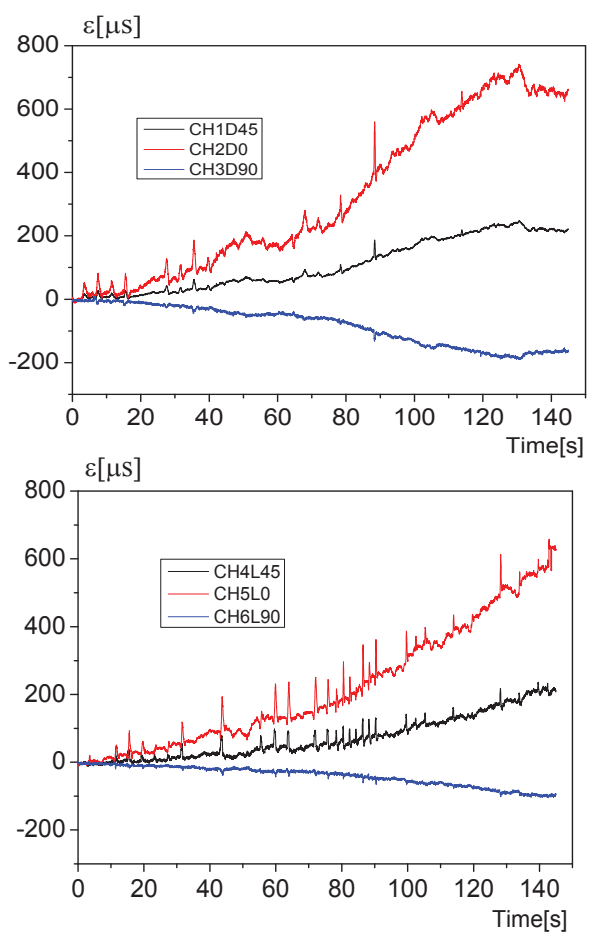

Fig. 6. Results from measurement 1.
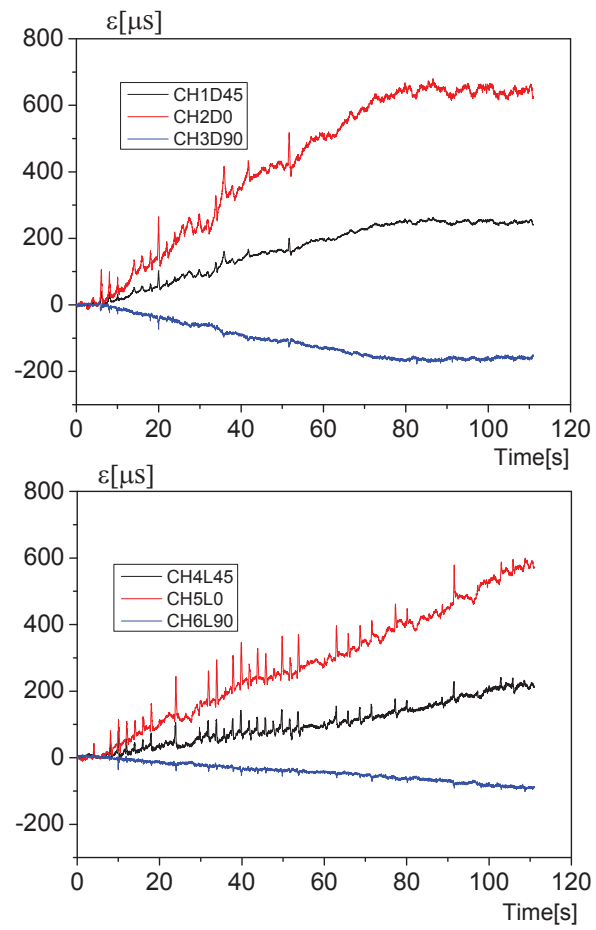

Fig. 7. Results from measurement 2.

The obtained results show that the dynamics of the process does not have any significant impact on the measured strains. The largest strains are at the end of the measurement (position 2).

Table 2 shows the results from the measured strains at the end of the data acquisition (position 2), the calculated principle stresses and the calculated von Mises stress in the vicinity of the test points.
Table 2. Results at the end of the data acquisition.

\begin{tabular}{|c|c|c|}
\hline № & Right link & Left link \\
\hline \multirow{4}{*}{1} & $\varepsilon_{a}=660.10^{-6}$ & $\varepsilon_{a}=632.10^{-6}$ \\
& $\varepsilon_{b}=224.10^{-6}$ & $\varepsilon_{b}=214.10^{-6}$ \\
\cline { 2 - 3 } & $\varepsilon_{c}=-161.10^{-6}$ & $\varepsilon_{c}=-99.10^{-6}$ \\
\cline { 2 - 3 } & $\sigma^{\prime}=140,1 \mathrm{MPa}=\sigma_{1}$ & $\sigma^{\prime}=138,3 \mathrm{MPa}=\sigma_{1}$ \\
& $\sigma^{\prime \prime}=5,4 \mathrm{MPa}=\sigma_{2}$ & $\sigma^{\prime \prime}=17,2 \mathrm{MPa}=\sigma_{2}$ \\
\cline { 2 - 3 } & $\sigma_{e k v}^{V M}=137,5 \mathrm{MPa}$ & $\sigma_{e k v}^{V M}=130,6 \mathrm{MPa}$ \\
\hline \multirow{4}{*}{2} & $\varepsilon_{a}=655.10^{-6}$ & $\varepsilon_{a}=580.10^{-6}$ \\
& $\varepsilon_{b}=254.10^{-6}$ & $\varepsilon_{b}=222.10^{-6}$ \\
\cline { 2 - 3 } & $\varepsilon_{c}=-162.10^{-6}$ & $\varepsilon_{c}=-89.10^{-6}$ \\
\cline { 2 - 3 } & $\sigma^{\prime}=138,9 \mathrm{MPa}=\sigma_{1}$ & $\sigma^{\prime}=126,6 \mathrm{MPa}=\sigma_{1}$ \\
& $\sigma^{\prime \prime}=4,9 \mathrm{MPa}=\sigma_{2}$ & $\sigma^{\prime \prime}=16,6 \mathrm{MPa}=\sigma_{2}$ \\
\cline { 2 - 3 } & $\sigma_{e k v}^{V M}=136,5 \mathrm{MPa}$ & $\sigma_{e k v}^{V M}=119,2 \mathrm{MPa}$ \\
\hline
\end{tabular}

\section{Numerical analysis}

The numerical analysis was performed with FEM, using SOLIDWORKS software.

The most appropriate model for FEA is the model shown in Fig. 8, which includes a link from the chain and the associated slat, using symmetry in geometry and loading. The mesh of finite elements and the boundary conditions are shown. The mesh of elements is created with mesh control in areas with a high stress gradient.

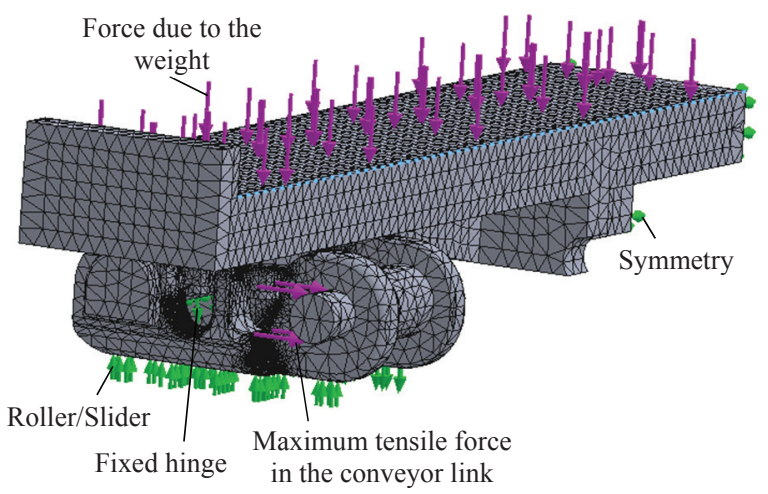

Fig. 8. FEA model.

The maximum tensile force in the conveyor link is calculated analytically [7]. It is calculated by taking into account the pull forces along the conveyor chain. The maximum of the force $\left(0,426 \cdot 10^{6} \mathrm{~N}\right)$ is in the top shaft.

Fig. 9 shows the von Mises stress from the numerical analysis. Values of the stress in the range of $115-130$ $\mathrm{MPa}$ are determined in the experimentally studied area. The areas with maximum stress correspond to the areas of destruction of the chain link. In these areas the highest stress values are determined in the range of $270-435$ $\mathrm{MPa}$. 


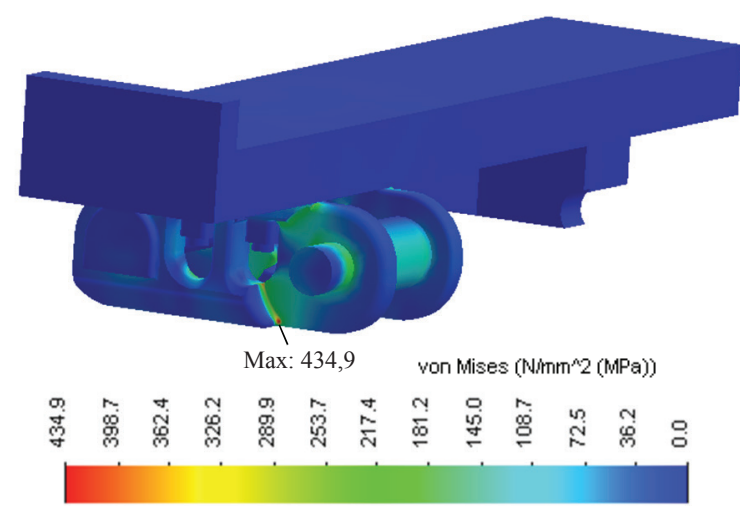

Fig. 9. Von Mises stress from the numerical analysis.

\section{Conclusion}

The comparison between the numerical analysis and experimental study shows a good match between the results. That gives us reason to assume that the results obtained with the numerical analysis are accurate. The numerical solution makes it possible to estimate stresses in all dangerous areas with geometric stress concentrators.

For a material yield strength of $640 \mathrm{MPa}$, the factor of safety turns out to be approximately 1,5 . This value is very low. The recommended value of the factor of safety, especially when the conveyor operates in aggressive dust and other contaminants, is in the order of 8 [1].

It is interesting to investigate the chain link with respect to fatigue.

\section{References}

1. N. Antonescu, Stresses in roller chain link plate, Rev. Roum Sci. Techn.-Mec. Appl., 20(2) 311-322, (1975)

2. S. Kale, R. Navthar, Analysis and optimization of chain conveyor outer link, Int. J. of innovative research in science, engineering and technology, 4(8), (2015)

3. S. Noguchi, K. Nagasaki, S. Nakayama, T. Kanda, T. Nishino, T. Ohtani, Static stress analysis of link plate of roller chain using finite element method and some design proposals for weight saving, Journal of advanced mechanical design, systems, and manufacturing, 3(2), 159-170, (2009)

4. M. Jagtap, B. Gaikwad, P. Pawar, B. Ronge, Use of strain gages to analyze the behavior of roller conveyor chain strip, International conference on computer science and mechanical engineering, Jaipur, India, 35-38, (2014)

5. R. Jeffrey, Conveyor chain designer guide, http://www.renold.com/upload/renoldswitzerland/c onveyor_chain_-_designer_guide.pdf.

6. L. Lazov, I. Slavov, Strength of materials, „Tehnika”, Sofia, in Bulgarian, (1992)

7. S. Nachev, Machines and equipment for continuous transport, Sofia, in Bulgarian, (1981) 